\title{
Comparison and evaluation of satellite derived precipitation products for hydrological modeling of the Zambezi River Basin
}

\author{
T. Cohen Liechti ${ }^{1}$, J. P. Matos ${ }^{1,2}$, J.-L. Boillat ${ }^{1}$, and A. J. Schleiss ${ }^{1}$ \\ ${ }^{1}$ Laboratory of Hydraulic Constructions (LCH), Ecole Polytechnique Fédérale de Lausanne (EPFL), \\ Station 18, 1015 Lausanne, Switzerland \\ ${ }^{2}$ SHRH, Instituto Superior Técnico (IST), Avda. Rovisco Pais, Lisboa, 1049-001, Portugal \\ Correspondence to: T. Cohen Liechti (theodora.cohen@epfl.ch)
}

Received: 11 August 2011 - Published in Hydrol. Earth Syst. Sci. Discuss.: 30 August 2011

Revised: 30 January 2012 - Accepted: 3 February 2012 - Published: 14 February 2012

\begin{abstract}
In the framework of the African DAms ProjecT (ADAPT), an integrated water resource management study in the Zambezi Basin is currently under development. In view of the sparse gauging network for rainfall monitoring, the observations from spaceborne instrumentation currently produce the only available rainfall data for a large part of the basin.

Three operational and acknowledged high resolution satellite derived estimates: the Tropical Rainfall Measuring Mission product 3B42 (TRMM 3B42), the Famine Early Warning System product 2.0 (FEWS RFE2.0) and the National Oceanic and Atmospheric Administration/Climate Prediction Centre (NOAA/CPC) morphing technique (CMORPH) are analyzed in terms of spatial and temporal repartition of the precipitations. They are compared to ground data for the wet seasons of the years 2003 to 2009 on a point to pixel basis at daily, 10-daily and monthly time steps and on a pixel to pixel basis for the wet seasons of the years 2003 to 2007 at monthly time steps.
\end{abstract}

The general North-South gradient of precipitation is captured by all the analyzed products. Regarding the spatial heterogeneity, FEWS pixels are much more inter-correlated than TRMM and CMORPH pixels. For a rainfall homogeneity threshold criterion of 0.5 global mean correlation coefficient, the area of each sub-basin should not exceed a circle of $2.5^{\circ}$ latitude/longitude radius for FEWS and a circle of $0.75^{\circ}$ latitude/longitude radius for TRMM and CMORPH considering rectangular meshes.

In terms of reliability, the correspondence of all estimates with ground data increases with the time step chosen for the analysis. The volume ratio computation indicates that
CMORPH is overestimating the rainfall by nearly $50 \%$. The statistics of TRMM and FEWS estimates show quite similar results.

Due to its lower inter-correlation and longer data set, the TRMM 3B42 product is chosen as input for the hydraulichydrologic model of the basin.

Further work will focus on the calibration of the hydraulichydrological model of the basin, including the major existing hydraulic structures with their operation rules.

\section{Introduction}

Water resource management in tropical and semi-arid areas of Africa is particularly important due to the high temporal and spatial climatic variability that affects the availability of water resources within and between countries and river basins. The overarching goal of the 'African DAms ProjecT: adapt planning and operation of large dams to meet social needs and environmental constraints' (ADAPT) is to strengthen this interdisciplinary science. A consistent information platform for a large scale river catchment, the Zambezi River basin, is currently under development. Modeling the hydrology of this basin is a challenging task due to its size and heterogeneity, but mostly due to the lack of reliable input and calibration data. In the past, several studies addressed the problem by using or assessing novel satellite derived data sources in addition to rainfall, such as evaporation (Winsemius et al., 2008), terrestrial water storage change (Winsemius et al., 2006b) and soil moisture (Meier et al., 2011). However, the satellite derived rainfall data were rarely 
evaluated even though, concerning model performance, the selection of the type of input precipitation has been considered as equally or even more important than the choice of the hydrological model.

In view of the sparse available gauging network for rainfall monitoring on the African continent, the observations from spaceborne instrumentation currently produce the only measured data for a large part of the territory. Two types of sensors are commonly used in the satellite rainfall estimation algorithms: Passive Microwave (PM) and Visible and Infrared Radiance (VIS/IR). The PM sensors identify the precipitation particles by the scattering due to large ice particles present in the clouds. These sensors are installed on Earthorbiting satellites which offer only intermittent coverage of a given region of interest (currently about ten observations per day). Therefore, the estimation of precipitation from proxy parameters such as cloud top temperature that can be inferred from geo-stationary observations has been developed. The algorithms based on IR data relate rainfall to cloud top temperature and cloud optical properties through a precipitation index. The indexing method assigns a fixed rain rate to each identified cloud type (Kidd, 2001). This assumption is most effective for convective conditions but can yield crude estimates because of the weak link between cloud properties and precipitation. Current approaches use rain rates estimated from coincident microwave observations to derive regional calibrations of Global-IR techniques (Anagnostou, 2004). However, both kinds of sensors have difficulties in capturing non-convective rainfall and shallow "warm" rain events (Ebert et al., 2007).

With multiple products currently available, it is important to evaluate their precision and uncertainty, as well as their advantages and drawbacks, before opting for a specific application. Several studies have been conducted with the aim to inter-compare, against locally observed data, rainfall estimates derived from satellite observations. On this issue, the work achieved by the International Precipitation Working Group (IPWG) (information available online at http://www.isac.cnr.it/ ipwg/) appears as a valuable reference. The project started in 2002 over Australia and the United States and an additional verification was undertaken over Europe in 2004. The results showed that PM-IR merged estimates perform about as well as radar in terms of daily precipitation bias and frequency over the United States (Ebert et al., 2007). Such elaborated evaluation has not, however, been undertaken over the African continent, as high quality networks of rain gauges and radars are needed in order to assess the performance of the estimates.

Nevertheless, the Tropical Rainfall Measuring Mission (TRMM) monthly estimates have been validated over major climatic regions in Africa (Adeyewa and Nakamura, 2003) showing the sensitivity of random and systematic error components to the seasonal and regional differences. Over West Africa, the TRMM-merged product seems to be in excellent agreement with gauge data at monthly time steps (Nicholson et al., 2003): the root mean square error is of the order of $1 \mathrm{mmday}^{-1}$ and there is no significant bias. Ten different satellite rainfall products, including TRMM 3B42, the Famine Early Warning System (FEWS) product (RFE2.0) and the National Oceanic and Atmospheric Administration/Climate Prediction Centre (NOAA/CPC) morphing technique (CMORPH), have been evaluated over East Africa's complex topography at monthly and 10-daily spatial resolutions (Dinku et al., 2007). Their relative root mean square error varies from 45 to $60 \%$, increasing as the time step decreases. FEWS RFE 2.0 performs worse than TRMM 3B42 because of the fixed temperature threshold and fixed rain rate used to compute IR estimates. CMORPH shows superior performance when compared to TRMM 3B42. The performance of seven operational global products, including TRMM 3B42, CMORPH, and FEWS RFE 2.0 was also evaluated during the West African monsoon at a 10-daily time step (Jobard et al., 2011). CMORPH exhibited the worst skills (strong positive bias), TRMM 3B42 displayed a moderate aptitude and FEWS RFE 2.0 the best performance in terms of distribution and bias. The Microwave Infra-Red Algorithm (MIRA) has been compared at a daily time scale to ground station data over Southern Africa (Layberry et al., 2006) showing better agreement in the wet months than in the drier ones, but overall quite poor skills for rainfall detection. Over the Okavango basin, a monthly dataset at $0.5^{\circ}$ based on the TRMM and Special Sensor Microwave Imager (SSM/I) datasets was found to overestimate the rainfall by $20 \%$ (Wilk et al., 2006). The comparison of MIRA and FEWS estimates to in situ station records over the Zambezi Basin at a monthly time scale indicated that MIRA often overestimates (up to $50 \%$ ) and produces rainfall during dry months whereas FEWS has less bias (Winsemius et al., 2006a). TRMM 3B42RT and CMORPH were evaluated over Ethiopian river basins (Romilly and Gebremichael, 2011; Bitew and Gebremichael, 2011) and CMORPH was found to underestimate rainfall by $11 \%$ whereas TRMM 3B42RT overestimated it by $5 \%$. However, the results varied depending on the geographical region considered.

Regarding the divergent results obtained from the previous studies and the lack of validation at the daily time step, the objective of this paper is to provide a comparison and an evaluation of the different sources of input data that can be used for hydrological modeling of the Zambezi Basin at a daily time step. Therefore, products with long time series were preferred. The aim of the analysis is to determine the appropriate size of sub-basins in terms of rainfall pattern and the reliable time step for modeling. Three operational and acknowledged high resolution (daily time step or smaller) and grid not coarser than $0.25^{\circ}$ satellite derived estimates (TRMM 3B42, FEWS RFE 2.0 and CMORPH) are analyzed and compared to ground data for the period from January 2003 to December 2009. The satellite derived datasets are available online without restriction and they fully cover 


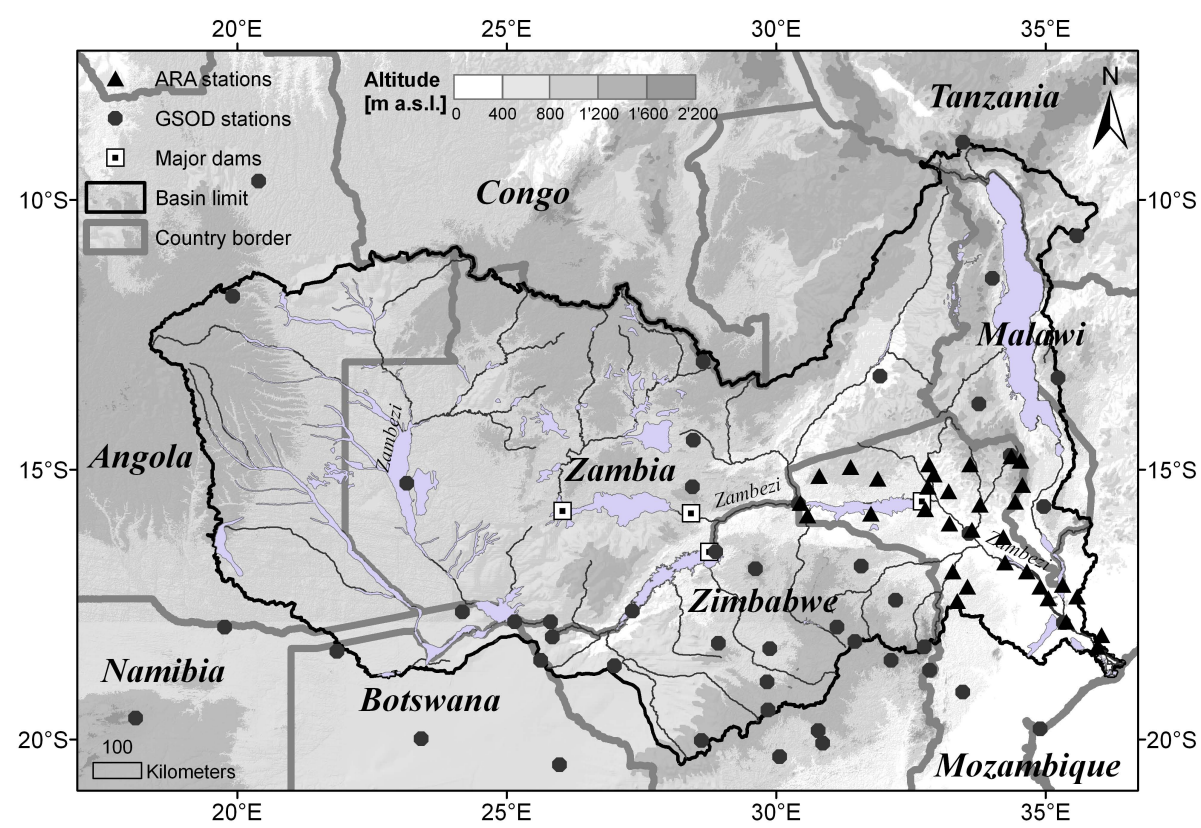

Fig. 1. Map of the Zambezi River Basin showing countries borders, main river network with lakes and flats, major dams and gauges with available rainfall observations for the period 1998 to 2009.

the region of interest. In Sect. 2, a brief description of the study area and the data used is given. The methodology applied is presented in Sect. 3, before the results are discussed in Sect. 4. Conclusions are drawn in Sect. 5.

\section{Study area and data}

\subsection{The Zambezi River Basin}

The Zambezi River Basin (Fig. 1), located in the South of the African continent, is shared by eight countries, making it a particularly interesting system on which to further investigate the implementation of IWRM's (Integrated Water Resources Management) principles. From its headwaters in Angola to the delta in Mozambique, the Zambezi River runs over $2600 \mathrm{~km}$ and connects eight African nations that share different portions of its $1.4 \mathrm{Mio} \mathrm{km}^{2}$ large drainage basin: Angola (18.3\%), Namibia (1.2\%), Botswana (2.8\%), Zambia (40.7\%), Zimbabwe (15.9\%), Malawi (7.7\%), Tanzania $(2.0 \%)$ and Mozambique (11.4\%) (Vörösmarty and Moore III, 1991). The basin lies fully within the tropics between $10^{\circ}$ and $20^{\circ} \mathrm{S}$, encompassing humid, semi-arid and arid regions dominated by seasonal rainfall patterns associated with the Inter-Tropical Convergence Zone (ITCZ). The ITCZ is a convective front oscillating along the equator. It moves from $6^{\circ} \mathrm{N}$ to $15^{\circ} \mathrm{S}$ from July to January and back North from February to June. Associated with it, the peak rainy season occurs during the Southern hemisphere summer (from October to April) and the winter months are dry. The diurnal cycle of precipitation depends also on the ITCZ.
Usually, clouds form in the late morning and early afternoon hours and then by the end of the afternoon, convectional short thunderstorms form and precipitation begins. In this study, the data from 32 Mozambican national rainfall gauges collected by the Regional Administration of Zambezi Water (ARA-Zambeze) and 48 rainfall gauges from the Global Summary Of the Day (GSOD) international database were collected, resulting in an unequally distributed dataset over the basin (Fig. 1).

The use of the potential of the Zambezi River is currently mainly limited to hydropower production through a series of large impoundments: the Kariba Dam, between Zambia and Zimbabwe; the Kafue hydropower scheme in Zambia; and the Cahora Bassa Dam in Mozambique.

\subsection{Rainfall estimates}

TRMM 3B42 version 6, NASA's standard precipitation product, has been produced since 1998 in four steps (Huffman et al., 2007): (1) PM estimates are calibrated and combined, (2) IR estimates are computed using PM estimates for calibration, (3) PM and IR estimates area combined, (4) data are rescaled to monthly total using Global Precipitation Climatology Centre (GPCC) data. The estimates are released on a $0.25^{\circ}$ by $0.25^{\circ}$ grid at a 3-hourly temporal resolution (00:00, 03:00, ..., 21:00 UTC) in a global belt extending from $50^{\circ} \mathrm{N}$ to $50^{\circ} \mathrm{S}$.

CMORPH is constructed from similar inputs as those used in TRMM 3B42 with the difference that it does not merge PM and IR rain estimates. At times and locations when PM data are unavailable, it uses the motion vector derived from 


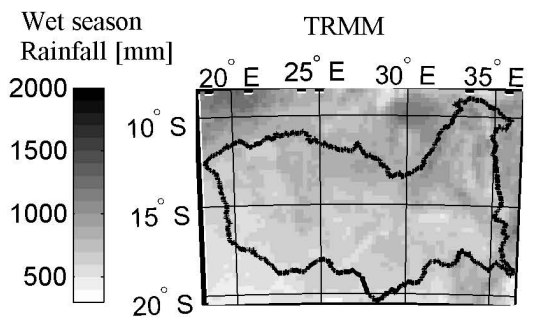

Dry season Rainfall [mm]

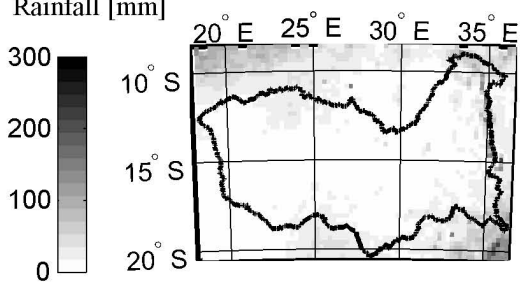

FEWS

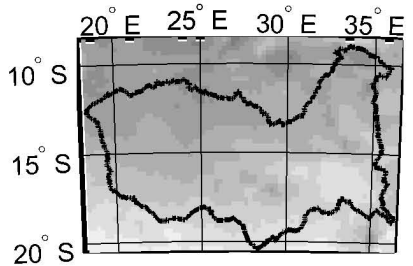

FEWS

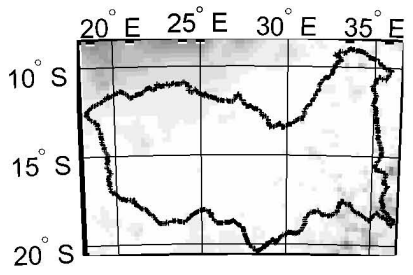

CMORPH

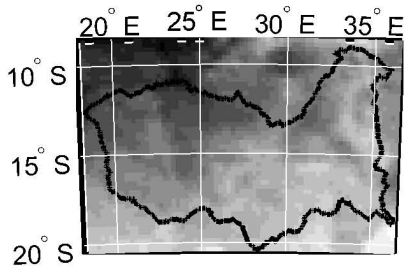

CMORPH

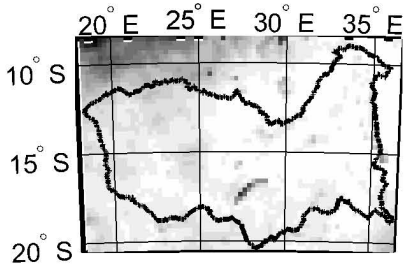

Fig. 2. Mean seasonal rainfall map for wet (top panels) and dry (bottom panels) periods for the three satellite estimates. Data analyzed from January 2003 to December 2009.

half-hourly geostationary satellite IR data to interpolate precipitation (Joyce et al., 2004). Therefore, the analysis does not rely on IR data for direct rainfall estimation. The original product, starting in December 2002, has a very high spatial resolution: $8 \mathrm{~km}$ grid and half-hourly time step. However, historical data are available only at a spatial resolution of $0.25^{\circ}$ and at a 3-hourly temporal resolution (00:00, 03:00, ..., 21:00 UTC) in a global belt extending from $60^{\circ} \mathrm{N}$ to $60^{\circ} \mathrm{S}$.

FEWS RFE is computed by the NOAA/CPC (Herman et al., 1997). Since January 2001, the version 2.0 of the algorithm has been used, integrating PM estimates. The data consist of a combination of PM and IR precipitation estimates merged with daily rainfall data from Global Telecommunication System (GTS) records. The spatial resolution corresponds to a $0.1^{\circ}$ grid which extends from $40^{\circ} \mathrm{N}$ to $40^{\circ} \mathrm{S}$ and $20^{\circ} \mathrm{W}$ to $55^{\circ} \mathrm{E}$. The time scale is daily (06:00-05:59 UTC). As precipitation mainly occurs in the afternoon, the time scale can be considered as 00:00 to 23:59 UTC. The algorithm contains rare high spikes in the precipitation estimates. Thus, the data have to be screened for intensities higher than a certain threshold.

The Global Precipitation Climatology Centre (GPCC) full data reanalysis product version 4 is based on synoptic weather observation data (SYNOP) and a monthly CLIMAT report received near real-time via the World Meteorological Organization (WMO) Global Telecommunication System (GTS) (7000-8000 stations). Additional data from dense national observation networks and global and regional collections complete the database which is the most comprehensive global compilation of monthly precipitation data from in situ observation (Schneider et al., 2008). The processing steps include quality-control, inter-comparison of the data from different sources and interpolation to a regular mesh $\left(0.5^{\circ}\right.$ grid). Version 4 of the product covers the period 1901 to 2007 at a monthly time step with varying data coverage.

The daily ground rainfall observations are extracted from the Global Surface Summary of the Day (GSOD) product archived by the National Climatic Data Centre (NCDC) of the NOAA. Historical data are generally available from 1929 to the present. In deriving the Summary of the Day data, a minimum of 4 observations per day must be present. The data are reported and summarized based on coordinated universal time (00:00-23:59 UTC). An extensive automated quality control is applied to correctly 'decode' as much of the synoptic data as possible, and to eliminate the random errors.

The ground rainfall data registered on a daily basis on the Mozambican part of the Zambezi basin are collected by the Regional Administration of Zambezi Water (ARA-Zambeze).

Table 1 summarizes the different characteristics of the rainfall estimates used.

\section{Methodology}

The first part of the analysis is the comparison of the different satellite estimates in order to bring out the similarities and discordances. The spatial distribution of rainfall for the dry season (from May to September) and the wet season (from October to April) is mapped on a grid of $0.25^{\circ}$ (Fig. 2). In addition, the zones of agreement and divergence between the different estimates are illustrated by correlation maps 
Table 1. Summary of the precipitation products used in this study with input data type, combination method and spatial and temporal resolution.

\begin{tabular}{|c|c|c|c|}
\hline Product name & Source data & Combination method & $\begin{array}{l}\text { Temporal and } \\
\text { spatial resolution }\end{array}$ \\
\hline $\begin{array}{l}\text { TRMM 3B42 } \\
\text { version } 6\end{array}$ & $\begin{array}{l}\text { Geo-IR, PM from } \\
\text { TMI, SSM/I, AMSU, } \\
\text { AMSR }\end{array}$ & $\begin{array}{l}\text { Combination of PM and } \\
\text { calibrated IR estimates, } \\
\text { monthly scaling on ground } \\
\text { station. }\end{array}$ & $\begin{array}{l}3 \text { hourly } \\
0.25^{\circ} \text { grid } \\
(1998-\text { present })\end{array}$ \\
\hline FEWS RFE2.0 & $\begin{array}{l}\text { Geo-IR, PM from } \\
\text { SSM/I and AMSU }\end{array}$ & $\begin{array}{l}\text { Combination of PM and IR } \\
\text { estimates, merging with daily } \\
\text { ground data. }\end{array}$ & $\begin{array}{l}\text { Daily } \\
0.1^{\circ} \text { grid } \\
(2002-\text { present })\end{array}$ \\
\hline CMORPH & $\begin{array}{l}\text { Geo-IR, PM from } \\
\text { TMI, SSM/I, AMSU, } \\
\text { AMSR }\end{array}$ & $\begin{array}{l}\text { Advection and evolution of } \\
\text { PM rain rates according to IR } \\
\text { imagery. }\end{array}$ & $\begin{array}{l}3 \text { hourly } \\
0.25^{\circ} \text { grid } \\
(2003 \text {-present })\end{array}$ \\
\hline $\begin{array}{l}\text { GPCC full data } \\
\text { reanalysis } \\
\text { product } \\
\text { version } 4\end{array}$ & $\begin{array}{l}\text { SYNOP, CLIMAT, } \\
\text { GHCN, CRU, FAO, } \\
\text { national } \\
\text { meteorological } \\
\text { services, ... }\end{array}$ & $\begin{array}{l}\text { Quality-control, inter- } \\
\text { comparison of the data from } \\
\text { different sources and } \\
\text { interpolation of the data to a } \\
\text { regular mesh system. }\end{array}$ & $\begin{array}{l}\text { Monthly } \\
0.5^{\circ} \text { grid } \\
(1901-2007)\end{array}$ \\
\hline GSOD version 7 & SYNOP & Quality control. & $\begin{array}{l}\text { Daily } \\
\text { (1929-present) }\end{array}$ \\
\hline $\begin{array}{l}\text { ARA-Zambeze } \\
\text { data }\end{array}$ & $\begin{array}{l}\text { National } \\
\text { meteorological } \\
\text { service }\end{array}$ & - & $\begin{array}{l}\text { Daily on the } \\
\text { Mozambican area } \\
\text { of the basin } \\
\text { (1945-present) }\end{array}$ \\
\hline
\end{tabular}
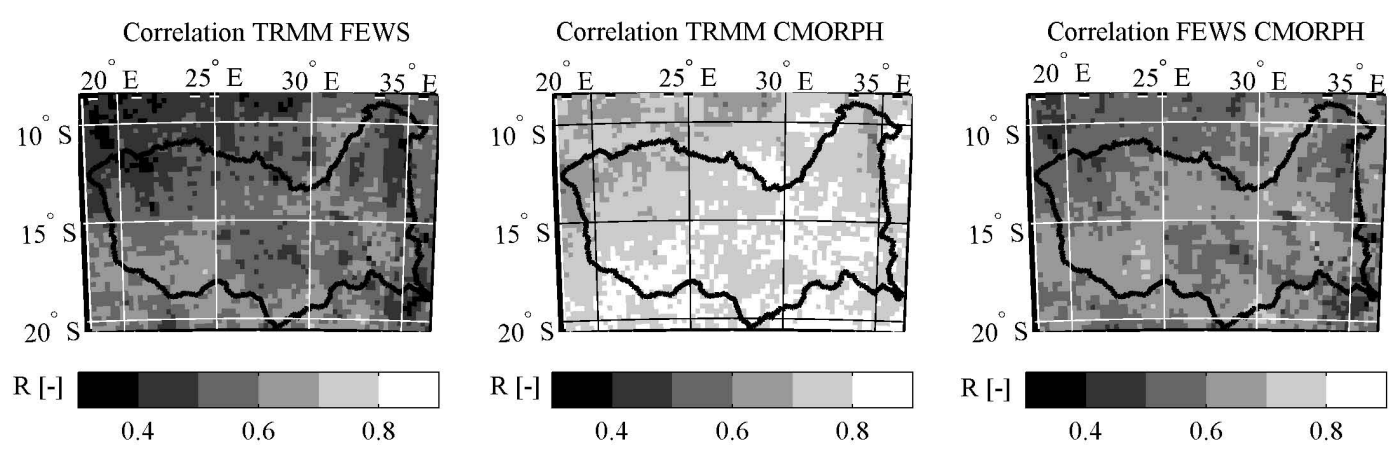

Fig. 3. Correlation maps $(R)$ of the three satellite estimates. Data analyzed from January 2003 to December 2009.

(Fig. 3). The Pearson correlation coefficient $(R)$ between two time series at the same pixel is used for computation.

$R(x, y)=\frac{\sum_{i=1}^{N}\left(x_{i}-\bar{x}\right) \cdot\left(y_{i}-\bar{y}\right)}{\sqrt{\sum_{i=1}^{N}\left(x_{i}-\bar{x}\right)^{2}} \cdot \sqrt{\sum_{i=1}^{N}\left(y_{i}-\bar{y}\right)^{2}}}$.

In view of an application for hydrological modeling, the average size of a rainfall event is assessed for each of the products by calculating mean temporal correlation (Pearson) on a squared ring 1 pixel wide at a distance of $r$ pixels from each pixel. The analysis is done assuming isotropy of the rainfall and over the period 2003 to 2009.

More precisely, for each pixel $p(i, j)$, the Pearson correlation coefficients are calculated between itself and all the other pixels:

$\operatorname{COR}_{p(i, j)}(k, l)=\operatorname{corr}(p(i, j), p(k, l))$

where $k$ and $l$ are the indexes of the pixel matrix, varying respectively between $18^{\circ}$ and $26^{\circ}$ longitude and $-8^{\circ}$ and $-20^{\circ}$ latitude. 

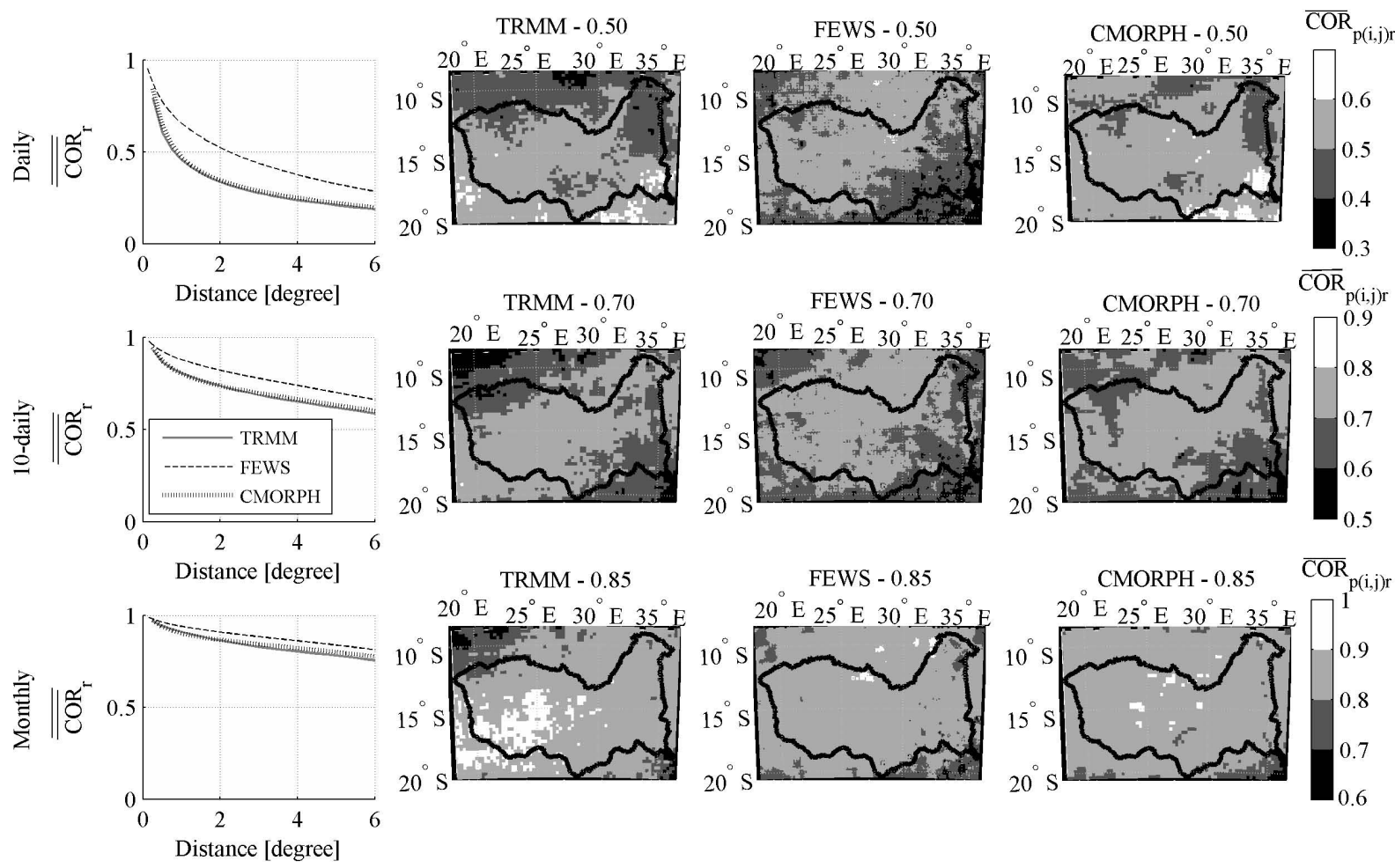

Fig. 4. Global correlation $\left(\overline{\overline{\mathrm{COR}}}_{r}\right)$ for the three estimates and map of correlation $\left(\overline{\mathrm{COR}}_{p(i, j) r}\right)$ at different squared ring for daily, 10-daily and monthly time steps. Data analyzed from January 2003 to December 2009.

The mean temporal correlation for each pixel at a distance $r$ is calculated by subtracting the mean correlation at a distance of $r-1$ pixels to the mean correlation at a distance of $r$ pixels.

$$
\begin{aligned}
\overline{\operatorname{COR}}_{p(i, j) r}= & \overline{\sum_{m=i-r}^{i+r} \sum_{n=j-r}^{j+r} \operatorname{COR}_{p(i, j)}(m, n)} \\
& -\sum_{s=i-(r-1)} \sum_{t=j-(r-1)}^{i+(r-1)} \operatorname{COR}_{p(i, j)}(s, t)
\end{aligned}
$$

where $i$ and $j$ define the position of the pixel inside the matrix and $r$ is the number of pixels corresponding to the ring of correlation varying from $0.01^{\circ}$ (FEWS FE2.0) or $0.25^{\circ}$ (TRMM and CMORPH) up to $6^{\circ}$ latitude/longitude.

The global mean correlation at each radius $\left(\overline{\overline{\mathrm{COR}}}_{r}\right)$ is then computed as an average over the whole basin to underline the differences between the estimates; and maps are produced for some of the key radiuses (Fig. 4). The analysis is done at daily, 10-daily and monthly time steps.

During the second part of the analysis, the error property of the satellite derived data with reference to point ground gauge measurements is investigated for the wet seasons of the years 2003 to 2009 (Table 2). As the ground data contain large gaps, only time series with at least 20 continuous daily
Table 2. Characteristics of the gauge data used for the pixel to point analysis.

\begin{tabular}{lclr}
\hline Time step & $\begin{array}{c}\text { Number of } \\
\text { gauges } \\
\text { (ARA/GSOD) }\end{array}$ & $\begin{array}{l}\text { Mean rainfall } \\
{[\mathrm{mm}]} \\
\text { (ARA/GSOD) }\end{array}$ & $\begin{array}{r}\text { Threshold } \\
{[\mathrm{mm}] \text { (for }} \\
\text { POD and FAR } \\
\text { calculation) }\end{array}$ \\
\hline Daily & $28 / 45$ & $3.8 / 3.2$ & 1 \\
10 daily & $28 / 30$ & $38.0 / 29.6$ & 10 \\
Monthly & $28 / 30$ & $114.8 / 89.2$ & 30 \\
\hline
\end{tabular}

values have been integrated in the analysis at a daily time step. For the 10-daily rainfall accumulation, one day of missing data is accepted in the calculation and for the monthly accumulation, up to 5 days of missing data are accepted. Since there is nearly no rain during the dry season, this period was not taken into account for the performance assessment. The goal of this analysis is to evaluate the quality of the satellite products and to select the most reliable for the hydrological modeling. As the products will be used for the hydrological modeling at their optimal spatial resolution, the original grid size is used for each product. The smaller grid size of FEWS could lead to better results, a fact taken into account in the analysis. 
Table 3. Characteristics of the global satellite versus gauge data series.

\begin{tabular}{lllll}
\hline $\begin{array}{l}\text { Indicator } \\
\text { (ARA/GSOD) }\end{array}$ & $\begin{array}{l}\text { Satellite } \\
\text { based } \\
\text { estimates }\end{array}$ & Daily & 10-Daily & Monthly \\
\hline Bias [mm] & TRMM & $0.09 /-0.11$ & $1.16 / 1.20$ & $2.94 / 9.04$ \\
& FEWS & $-0.32 /-0.06$ & $-2.98 / 2.17$ & $-9.28 / 10.01$ \\
& CMORPH & $0.67 / 00.41$ & $7.25 / 5.97$ & $22.31 / 25.22$ \\
\hline Correlation [-] & TRMM & $0.23 / 0.28$ & $0.6 / 0.71$ & $0.69 / 0.83$ \\
& FEWS & $0.21 / 0.21$ & $0.62 / 0.83$ & $0.67 / 0.89$ \\
& CMORPH & $0.22 / 0.25$ & $0.62 / 0.64$ & $0.69 / 0.67$ \\
\hline Sample size & TRMM & $21333 / 27600$ & $2083 / 1905$ & $683 / 625$ \\
& FEWS & $21333 / 27600$ & $2083 / 1905$ & $683 / 625$ \\
& CMORPH & $21265 / 27514$ & $2044 / 1859$ & $646 / 584$ \\
\hline
\end{tabular}
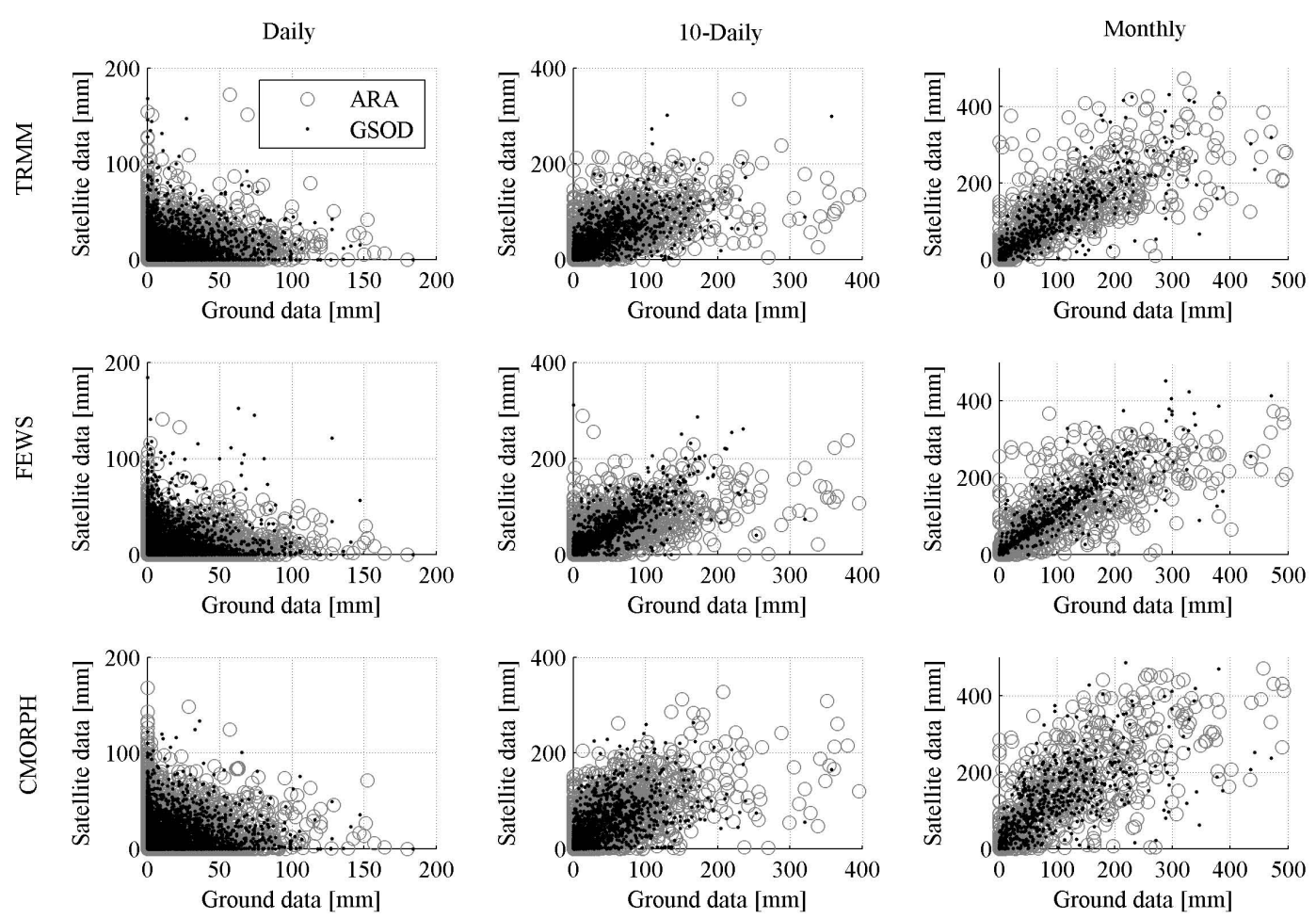

Fig. 5. Scatter plot of satellite based estimates versus ground data for daily, 10-daily and monthly time steps for the period 2003 to 2009.

The two ground data sets, GSOD and ARA, are separated for the analysis as they come from different sources and do not cover the same area of the basin. Both sets of data (satellite product versus gauge data) are plotted at daily, 10-daily and monthly time steps for the pixels on which at least one gauge is available (Fig. 5). The associated global characteristics: correlation $(R)$, bias (Eq. 4) and sample size are listed in Table 3.

Bias $=\frac{\sum(\text { Sat }- \text { Obs })}{N}$ where "Sat" is the satellite data, "Obs" the ground observed data and $N$ the sample size.

Statistics are calculated for each of the gauges, weighted by the number of available data per season, and a global value of the coefficients is determined by the weighted mean of all gauges based on the total number of records per gauge.

The ability for each of the products to detect rainfall is evaluated by the Probability Of Detection (POD) and the False Alarm Ratio (FAR) indices (Layberry et al., 2006; Stanski et al., 1989; Ebert et al., 2007). For each rainfall 

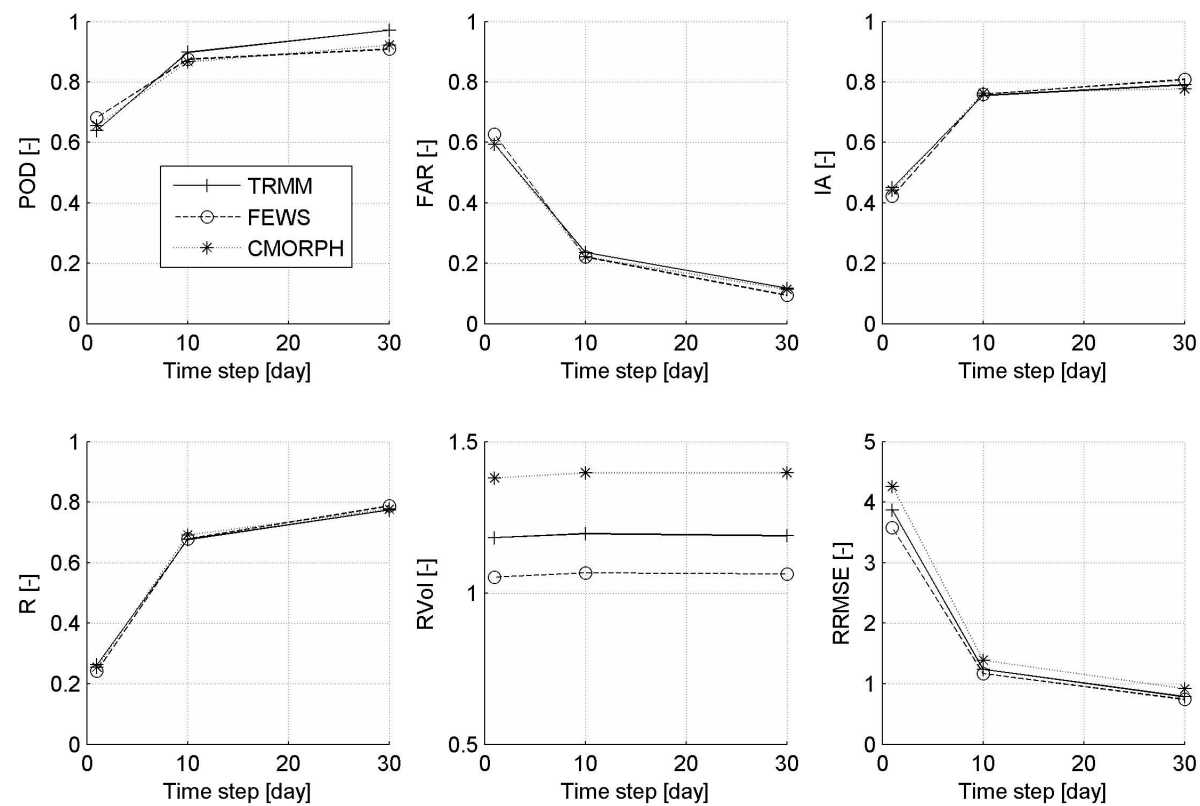

Fig. 6. Statistics for the ARA-Zambeze gauges. Data analyzed from January 2003 to December 2009. POD: probability of detection, FAR: false alarm ratio, $R$ : correlation coefficient, RVol: volume ratio, RRMSE: relative root mean square error.

threshold (in $\mathrm{mm}$ ) associated with a time step (Table 2) and at each point, it is estimated to have rained or not. This leads to three outcomes: estimated rain/observed rain (hit, $h$ ), estimated rain/observed no rain (false alarm, $f$ ) and estimated no rain/observed rain (miss, $m$ ). The indicators are derived from these outcomes:

$\mathrm{POD}=\frac{h}{h+m}$

$\mathrm{FAR}=\frac{f}{h+f}$

The precision of the satellite products is evaluated by the Relative Root Mean Square Error (RRMSE), the Pearson coefficient of correlation $(R)$, the Volume Ratio (RVol) and the Index of agreement (IA) (Daren Harmel and Smith, 2007) (Figs. 6 and 7).

RRMSE $=\frac{\sqrt{\frac{1}{N} \sum(\mathrm{Sat}-\mathrm{Obs})^{2}}}{\overline{\mathrm{Obs}}}$

$\mathrm{RVol}=\frac{\sum \mathrm{Sat}}{\sum \mathrm{Obs}}$

$\mathrm{IA}=\frac{\sum(\mathrm{Sat}-\mathrm{Obs})^{2}}{\sum(|\mathrm{Sat}-\overline{\mathrm{Obs}}|+|\mathrm{Obs}-\overline{\mathrm{Obs}}|)^{2}}$

where "Sat" is the satellite data, "Obs" the ground observed data and $\overline{\mathrm{Obs}}$ the mean of the ground observed data.

Finally, the pixel to pixel approach is applied to the satellite products in comparison with the GPCC ground data grid,
Table 4. Characteristics of the global satellite versus GPCC series.

\begin{tabular}{llll}
\hline Indicator & TRMM & FEWS & CMORPH \\
\hline Bias [mm] & -11.25 & -5.96 & 25.28 \\
Correlation & 0.80 & 0.84 & 0.76 \\
Sample size & 3225 & 3225 & 3017 \\
\hline
\end{tabular}

taking into account only the pixels with at least one gauge. The data are compared by means of scatter plots (Fig. 8) and maps of volume ratio (Fig. 9) in order to evaluate the spatial distribution of the satellite precision. The global correlation, bias and sample size of the scatter plots are listed in the Table 4.

\section{Results and discussion}

\subsection{Temporal and spatial repartition of the precipitation}

The spatial variation analysis shows a general North-South gradient in the intensity of precipitation (Fig. 2). The TRMM data set registers slightly lower rainfall intensities than the FEWS data set. The region of Lake Malawi, located in North-East side, is characterized by lower rainfall in comparison with the North-West area. The grid pixels above the ocean (South-East corner) reveal lower rainfall than those of the coastal areas. CMORPH displays the highest spatial 

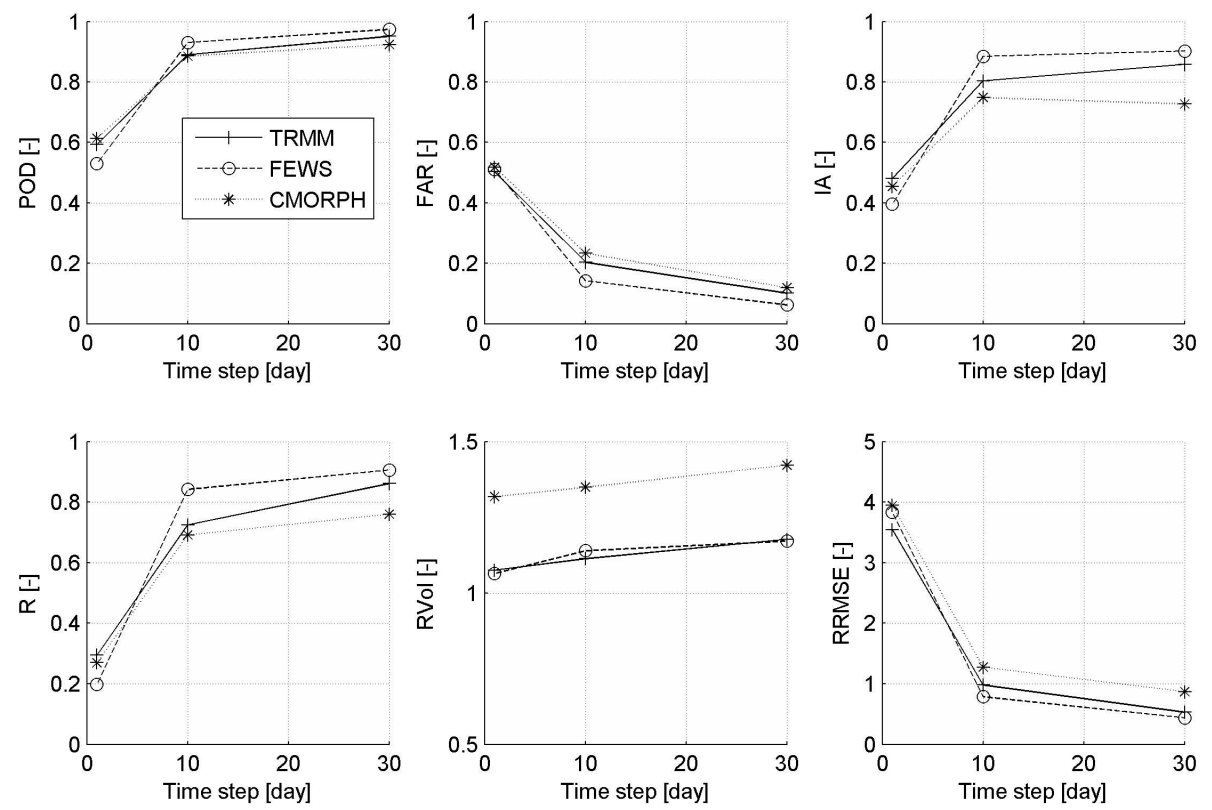

Fig. 7. Statistics for the GSOD gauges. Data analyzed from January 2003 to December 2009. POD: probability of detection, FAR: false alarm ratio, $R$ : correlation coefficient, RVol: volume ratio, RRMSE: relative root mean square error.
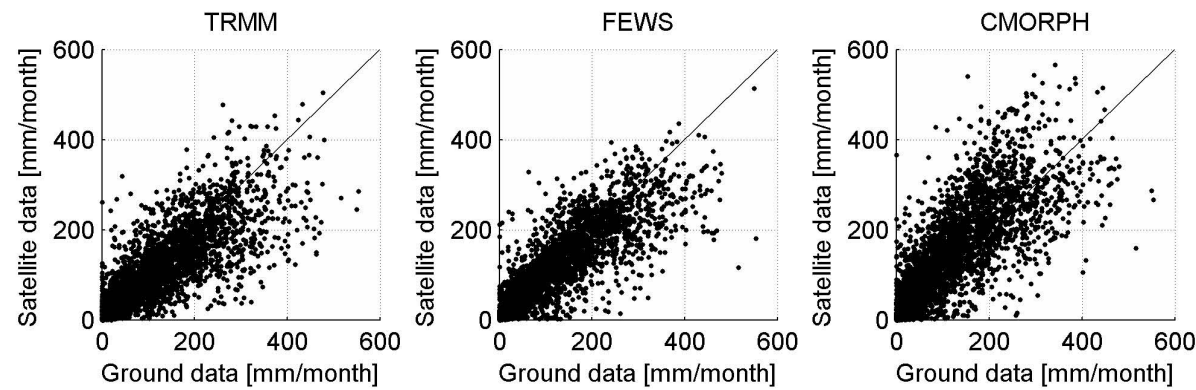

Fig. 8. Scatter plot of satellite estimates versus GPCC data at a monthly time step for the period 2003 to 2007.

variability of the rainfall, varying from 300 to $2000 \mathrm{~mm} \mathrm{yr}^{-1}$, and seems to overestimate the precipitated amount in the North-West region. During the dry season, it displays quite high rainfall intensities over the Kariba Lake area, probably due to some shortcomings in the computation procedure. FEWS reports both the lowest volume and the lowest variability of the three rainfall estimates. TRMM's spatial variability is moderate. Although the main characteristics of the rainfall are preserved in all estimates, its spatial patterns produced by the three algorithms show considerable differences.

The global correlation coefficients are 0.54 between TRMM and FEWS data sets, 0.76 between TRMM and CMORPH and 0.60 between FEWS and CMORPH. In terms of spatial repartition (Fig. 3), the area at the North-West corner, the region over Lake Malawi (North-East limit of the basin) and the coast line (South-East corner) show the lowest agreement between data sets. The overall low correlation $(R)$ between TRMM and FEWS as well as between FEWS and
CMORPH is probably due to the difference in the IR-based estimates used in the algorithm. TRMM and CMORPH have the highest global correlation, which reflects that their algorithms are based on the same PM data and can indicate that the IR influence is not very important.

The homogeneity of the rainfall was evaluated through the correlation of the time series in each pixel with those of the surrounding pixels. FEWS exhibits the highest internal correlation $\left(\overline{\overline{\mathrm{COR}}}_{r}\right)$, and is different from TRMM and CMORPH, which show similar patterns to each other (Fig. 4). At a daily time step, FEWS has a mean correlation of 0.5 computed on a radius of $2.25^{\circ}$ and the mean correlation of TRMM and CMORPH decreases rapidly with a correlation of 0.5 on a radius of only $0.75^{\circ}$. The spatial repartition of the correlation coefficient $\left(\overline{\mathrm{COR}}_{p(i, j) r}\right)$ is different from one estimate to the other; however, regardless of the product, the central part of the basin seems to be homogeneous and the region over Malawi Lake rather heterogeneous. 

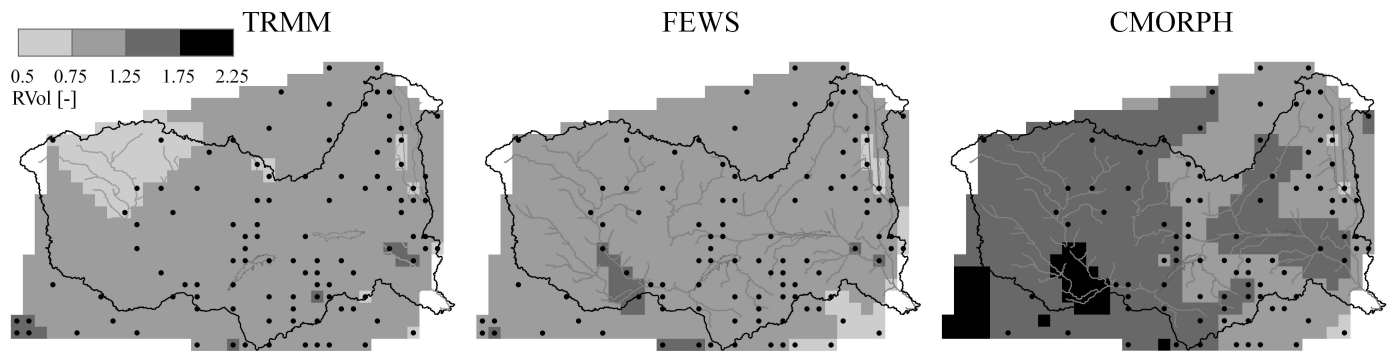

Fig. 9. Spatial repartition of the volume ratio (RVol) for TRMM, FEWS and CMORPH estimates versus GCPP data at a monthly time step for the period 2003 to 2007.

At a 10-daily time step, the 0.7 correlation pattern is similar for all the products: the area over the ocean has the highest heterogeneity along with the regions over Lake Malawi and the upper West corner of the basin. The zones of homogeneity over the delta present at the daily time step for TRMM and CMORPH do not appear at the 10-daily time step.

At a monthly time step, the difference between the products for the global correlation is close to zero. In terms of spatial pattern, the area over the ocean is still a heterogeneous zone for all the products. TRMM exhibits a high correlation over the Western part of the basin whereas Kariba Lake is an area of high heterogeneity for CMORPH.

\subsection{Validation of the satellite estimates on ground data}

\subsubsection{Point to pixel}

Based on the scatter plots presented in Fig. 5, it is clear that the time step has an important influence on the quality of the satellite estimates. At a daily time step, no direct correlation exists between the satellite estimates and the ground data, whereas monthly accumulation comparisons already display a marked trend.

Especially at 10-daily and monthly time steps, TRMM and FEWS estimates are less correlated with the ARA-Zambeze data than with the GSOD data (Table 3). The global correlation is about 0.6 at the 10-daily time step for both estimates compared to ARA-Zambeze data, and reaches respectively 0.7 and 0.8 for TRMM and FEWS compared to GSOD data. FEWS has the lower dispersion as the algorithm uses GSOD data to rescale the satellite estimates. The TRMM product has the lowest bias but an important dispersion of the cloud. A strong overestimation is visible on the CMORPH cloud, confirmed by a global bias of about $24 \mathrm{~mm}$ at the monthly time step (Table 3).

The statistics for the ARA-Zambeze data are presented on Fig. 6. All the satellite products reach similar values, except for the volume ratio, for which CMORPH is overestimating the rainfall by about $40 \%$, TRMM is overestimating the rainfall by about $20 \%$ and FEWS is close to 1 . CMORPH's strong positive bias has already been documented for West Africa (Jobard et al., 2011). However, it seems to be more reliable over Ethiopia where it performs better than TRMM 3B42 and FEWS RFE2.0 at the 10-daily time step (Dinku et al., 2007) and underestimates the rainfall by $11 \%$ at the daily time step (Romilly and Gebremichael, 2011). As the time step increases, the performance of the estimates also increases (higher POD, IA and $R$ and lower FAR and RRMSE). This is consistent with the results already published in terms of time step effect. The highest performance of FEWS may be due to its smaller grid size as it reduces the effect of pixel to point comparison.

For the GSOD data (Fig. 7), the differences between the satellite estimates are more marked. At 10-daily and monthly time steps, the POD, FAR, $R$ and IA of FEWS are the best, followed by the statistics of the TRMM data. In terms of volume ratio, CMORPH is still showing an overestimation of about $40 \%$ but FEWS and TRMM have similar values, both close to 1 .

\subsubsection{Pixel to pixel}

The pixel to pixel comparison, carried out for a monthly time step on GPCC's $0.5^{\circ}$ grid (Fig. 8 and Table 4), shows the same trend as the point to pixel analysis. CMORPH is clearly overestimating the rainfall as the cloud of scatter plot points falls to the left side of the plot and the global bias reaches $25 \mathrm{~mm}$. FEWS has the lowest dispersion of the cloud, the lowest bias $(-6 \mathrm{~mm})$ and the highest correlation $(0.84)$.

Regarding the spatial distribution of the satellite performance (Fig. 9), the precipitations are overestimated in the South-West corner, especially with CMORPH (volume ratio of about 2). On the contrary, an underestimation (below 0.75 ) occurs on some pixels over the Malawi Lake for all the estimates. For FEWS and TRMM, the major part of the basin has a volume ratio between 0.75 and 1.25 .

\section{Conclusions}

First, the three satellite estimates were compared. In terms of yearly rainfall, although main characteristics are preserved, the rainfall spatial patterns produced by the three algorithms show considerable differences. CMORPH seems to be highly 
influenced by the Kariba Lake. Regarding the spatial heterogeneity, FEWS pixels are much more inter-correlated than TRMM pixels. For a rainfall homogeneity threshold criterion of 0.5 global mean correlation coefficient, the area of each sub-basin should not exceed a circle of $2.5^{\circ}$ latitude/longitude radius for FEWS and a circle of $0.75^{\circ}$ latitude/longitude radius for TRMM and CMORPH considering a rectangular mesh.

Secondly, the performance of the satellite estimates was assessed by comparisons with ground gauges. However, the satellite estimates cannot be expected to provide results identical to the gauge measurements as both the temporal and the spatial samplings are different. The gauging stations provide point measurements observed over continuous periods of time, while satellites deliver spatial averages based on intermittent rain rate estimates, having a tendency to smooth localized phenomena which can substantially affect gauging stations. Because of their lack of areal representativeness, the gauge measurements cannot be treated as the ground truth reference for the area-averaged rainfall. Therefore, as suggested in the literature (Wang and Wolff, 2010), the difference between satellite estimates and gauge measures should be separated into the gauge area-point error variance and satellite-rain estimation error variance. In another perspective, the reliability of gauge data is also controversial because the series are often not continuous and subject to many possible error sources such as mechanical problems, interferences in the sampling mechanism or inadequate calibration (Sieck et al., 2007). Since the gauge data used in this study are not exempt of inherent errors and the area-point estimation error is not taken into account, the ground data are not considered as a perfect measure but rather as a comparator for the satellite estimates. At a daily time scale, the probability of rainfall being detected by the satellite appears nearly equivalent to a random simulation (POD of about 0.6 and FAR of about 0.5 ). At a monthly time scale, all estimates have a good correspondence, CMORPH being less precise in terms of volume ratio as it overestimates the rainfall by about $40 \%$. TRMM 3B42 and FEWS RFE2.0 show a very similar performance compared to ground data even if they are very different in the spatial repartition of the rainfall.

The objective of the research is to assess different scenarios of water use over the Zambezi River Basin using a calibrated hydrological model. The datasets are thus candidates for post-real-time research. Therefore, as TRMM produces data since 1998, which will increase the number of years available for calibration and validation of the model, it is chosen as the input data for hydrological modeling.

The results presented in this paper underline the fact that rainfall input data have to be studied before modeling the hydrological behavior of a basin in order to know the size of rainfall events and their distribution through space and time. Moreover, they illustrate the very strong dependency of the satellite product quality on the region of interest. An interesting addition to the study would be to calibrate the model with the different possible input data and evaluate the performance in terms of runoff simulation. However, in a basin like the Zambezi, one where only about $7 \%$ of the rainfall is contributing to runoff, the influence of other parameters like the wetland capacity, the evaporation and soil equations will be more important.

Acknowledgements. The study represents part of the research project ADAPT funded by the Competence Centre Environment and Sustainability of the ETH Domain (CCES). The authors thank Dinis Juizo of Universidade Eduardo Mondlane for his advice about the data analysis during his stay as an academic guest at EPFL Switzerland; as well as the ARA-Zambeze team for their support and the provided data.

Edited by: N. Verhoest

\section{References}

Adeyewa, Z. D. and Nakamura, K.: Validation of TRMM radar rainfall data over major climatic regions in Africa, J. Appl. Meteorol., 42, 331-347, 2003.

Anagnostou, E. N.: Overview of overland satellite rainfall estimation for hydro-meteorological applications, Surv. Geophys., 25, 511-537, 2004.

Bitew, M. M. and Gebremichael, M.: Assessment of satellite rainfall products for streamflow simulation in medium watersheds of the Ethiopian highlands, Hydrol. Earth Syst. Sci., 15, 11471155, doi:10.5194/hess-15-1147-2011, 2011.

Daren Harmel, R. and Smith, P. K.: Consideration of measurement uncertainty in the evaluation of goodness-of-fit in hydrologic and water quality modeling, J. Hydrol., 337, 326-336, 2007.

Dinku, T., Ceccato, P., Grover-Kopec, E., Lemma, M., Connor, S. J., and Ropelewski, C. F.: Validation of satellite rainfall products over East Africa's complex topography, Int. J. Remote Sens., 28, 1503-1526, 2007.

Ebert, E. E., Janowiak, J. E., and Kidd, C.: Comparison of nearreal-time precipitation estimates from satellite observations and numerical models, B. Am. Meteorol. Soc., 88, 47-64, 2007.

Herman, A., Kumar, V. B., Arkin, P. A., and Kousky, J. V.: Objectively determined 10-day African rainfall estimates created for Famine Early Warning Systems, Int. J. Remote Sens., 18, 21472159, 1997.

Huffman, G. J., Adler, R. F., Bolvin, D. T., Gu, G., Nelkin, E. J., Bowman, K. P., Hong, Y., Stocker, E. F., and Wolff, D. B.: The TRMM multisatellite precipitation analysis (TMPA): Quasiglobal, multiyear, combined-sensor precipitation estimates at fine scales, J. Hydrometeorol., 8, 38-55, 2007.

Jobard, I., Chopin, F., Berges, J. C., and Roca, R.: An intercomparison of 10-day satellite precipitation products during West African monsoon, Int. J. Remote Sens., 32, 2353-2376, 2011.

Joyce, R. J., Janowiak, J. E., Arkin, P. A., and Xie, P.: CMORPH: A method that produces global precipitation estimates from passive microwave and infrared data at high spatial and temporal resolution, J. Hydrometeorol., 5, 487-503, 2004.

Kidd, C.: Satellite rainfall climatology: A review, Int. J. Climatol., 21, 1041-1066, 2001. 
Layberry, R., Kniveton, D. R., Todd, M. C., Kidd, C., and Bellerby, T. J.: Daily precipitation over Southern Africa: A new resource for climate studies, J. Hydrometeorol., 7, 149-159, 2006.

Meier, P., Frömelt, A., and Kinzelbach, W.: Hydrological real-time modelling in the Zambezi river basin using satellite-based soil moisture and rainfall data, Hydrol. Earth Syst. Sci., 15, 9991008, doi:10.5194/hess-15-999-2011, 2011.

Nicholson, S. E., Some, B., McCollum, J., Nelkin, E., Klotter, D., Berte, Y., Diallo, B. M., Gaye, I., Kpabeba, G., Ndiaye, O., Noukpozounkou, J. N., Tanu, M. M., Thiam, A., Toure, A. A., and Traore, A. K.: Validation of TRMM and other rainfall estimates with a high-density gauge dataset for West Africa. Part ii: Validation of trmm rainfall products, J. Appl. Meteorol., 42, 1355-1368, 2003.

Romilly, T. G. and Gebremichael, M.: Evaluation of satellite rainfall estimates over Ethiopian river basins, Hydrol. Earth Syst. Sci., 15, 1505-1514, doi:10.5194/hess-15-1505-2011, 2011.

Schneider, U., Fuchs, T., Meyer-Christoffer, A., and Rudolf, B.: Global precipitation analysis products of the GPCC, Global Precipitation Climatology Centre, Germany, 2008.

Sieck, L. C., Burges, S. J., and Steiner, M.: Challenges in obtaining reliable measurements of point rainfall, Water Resour. Res., 43, W01420, doi:10.1029/2005WR004519, 2007.

Stanski, H. R., Wilson, L. J., and Burrows, W. R.: Survey of common verification methods in meteorology, World weather watch tech. Rep. 8, WMO/TD No. 358, Geneva, Switzerland, 1989.
Vörösmarty, C. J. and Moore III, B.: Modeling basin-scale hydrology in support of physical climate and global biogeochemical studies: An example using the Zambezi River, Surv. Geophys., 12, 271-311, 1991.

Wang, J. and Wolff, D. B.: Evaluation of TRMM ground-validation radar-rain errors using rain gauge measurements, J. Appl. Meteorol. Clim., 49, 310-324, 2010.

Wilk, J., Kniveton, D., Andersson, L., Layberry, R., Todd, M. C., Hughes, D., Ringrose, S., and Vanderpost, C.: Estimating rainfall and water balance over the Okavango River Basin for hydrological applications, J. Hydrol., 331, 18-29, 2006.

Winsemius, H. C., Savenije, H. H. G., Gerrits, A. M. J., Zapreeva, E. A., and Klees, R.: Comparison of two model approaches in the Zambezi river basin with regard to model reliability and identifiability, Hydrol. Earth Syst. Sci., 10, 339-352, doi:10.5194/hess10-339-2006, 2006 a.

Winsemius, H. C., Savenije, H. H. G., Van De Giesen, N. C., Van Den Hurk, B. J. J. M., Zapreeva, E. A., and Klees, R.: Assessment of gravity recovery and climate experiment (grace) temporal signature over the Upper Zambezi, Water Resour. Res., 42, W12201, doi:10.1029/2006WR005192, 2006b.

Winsemius, H. C., Savenije, H. H. G., and Bastiaanssen, W. G. M.: Constraining model parameters on remotely sensed evaporation: justification for distribution in ungauged basins?, Hydrol. Earth Syst. Sci., 12, 1403-1413, doi:10.5194/hess-12-14032008, 2008. 